\title{
Faktor Organisasi yang Mempengaruhi Pelaksanaan Audit Maternal
}

\author{
Prita Muliarini* \\ Pascasarjana Manajemen Universitas Merdeka Malang dan HOGSI Malang \\ Jl. Terusan Raya Dieng No.59 Malang, Indonesia \\ drpritamuliarini@yahoo.com
}

Edi Sumarsono

Pascasarjana Manajemen Universitas Merdeka Malang

Jl. Terusan Raya Dieng No.59 Malang, Indonesia

edisumarsono.skep@yahoo.com

Diterima: 09-02-2021

Disetujui: 16-06-2021

Dipublikasi: 30-06-2021

\begin{abstract}
ABSTRAK
Audit maternal adalah bagian dari perubahan dalam organisasi perawatan kesehatan. Namun birokrasi yang rumit dan kaku mengakibatkan organisasi kesulitan menerima perubahan tanpa bukti ilmiah yang jelas dan meyakinkan. Angka kematian ibu yang masih tinggi menunjukkan bahwa audit ibu belum optimal. Seringkali rekomendasi audit tidak dilaksanakan sehingga perubahan yang diharapkan tidak terjadi. Kajian ini bertujuan untuk menemukan aspek organisasi yang kurang optimal dalam pelaksanaan audit untuk mendorong semua pihak berkolaborasi dalam perubahan yang berkelanjutan, terarah dan terencana. Penelitian ini merupakan penelitian kualitatif dengan pendekatan review naratif dengan menggunakan data sekunder dari tujuh artikel sebelumnya. Artikel dianalisis untuk menemukan berbagai hambatan dan kendala pada audit maternal, kemudian dikategorikan berdasarkan konteks perilaku organisasi yaitu individu, kelompok dan struktur. Penelitian ini mengidentifikasi kompleksitas dalam audit maternal dan keterkaitan antara aspek individu, kelompok dan struktural, termasuk masalah persekusi, perilaku kooperatif yang rendah, dan kebijakan politik. Hal tersebut berdampak besar pada upaya penurunan angka kematian ibu. Oleh karena itu diperlukan intervensi klinis dan non klinis, serta politis dalam mempercepat penurunan angka kematian ibu. Penyusunan kebijakan, proses analisis, dan tindak lanjut audit maternal harus melibatkan setiap elemen organisasi, baik individu maupun kelompok, dalam struktur organisasi.
\end{abstract}

Keywords:

Audit Maternal, Hambatan Audit Maternal, Perilaku Organisasi, Perubahan Organisasi

\begin{abstract}
Maternal audits are part of a change in health care organizations. However, complicated and rigid bureaucracy resulting in difficulties for the organization to accept change without clear and convincing scientific evidence. The maternal mortality remains high, indicating that the maternal audit is not optimal. Often audit recommendations are not implemented so that the expected changes do not occur. This study aims to find suboptimal organizational aspects in the implementation of audits to encourage all parties to collaborate in sustainable, targeted and planned changes. This is a qualitative research with a narrative review approach using secondary data from the previous seven articles. Articles were analyzed to find various obstacles and constraints on maternal audit, and then categorized based on the context of organizational behavior, namely individual, group and structure. This study identified complexities in maternal auditing, interrelated between individual, group and structural aspects, including problems of persecution, low cooperative behavior, and political policies. Those have a major impact on efforts to reduce maternal mortality. Therefore, it requires clinical and non-clinical interventions, as well as political, in accelerating the reduction of maternal mortality. The arrangement of policies, analysis processes, and follow-up on maternal audits must involve every element of the organization, both individuals and groups, in the organizational structure.
\end{abstract}

Keywords:

Maternal Audit; Obstacles Of Maternal Audit; Organizational Behavior; Organizational Change

\footnotetext{
*Corresponding author
} 


\section{PENDAHULUAN}

Audit maternal merupakan bentuk keikutsertaan pemerintah dalam program World Health Association (WHO), yaitu maternal death surveillance and response (MDSR) (WHO, 2016). Namun, pelaksanaan audit maternal di Indonesia masih belum berhasil menurunkan angka kematian ibu dan bayi di Indonesia (Kementerian Kesehatan Republik Indonesia, 2016)' karena angka kematian ibu di Indonesia masih merupakan yang tertinggi di Asia Tenggara, yaitu diperkirakan berada antara 126 hingga 359 kematian ibu setiap 100.000 kelahiran hidup (KH) (WHO, UNICEF, UNFPA, World Bank, \& United Nations Population Division, 2015). Sedangkan Survei Penduduk Antas Sensus (SUPAS) 2015 menemukan bahwa angka kematian ibu di Indonesia berada pada angka 305/100000 kelahiran hidup ( Badan Pusat Statistik, 2015). Fasilitas kesehatan seringkali tidak me-review kematian ibu untuk menentukan kesenjangan dalam layanan dan melakukan tindakan korektif. Meskipun diamanatkan oleh Kemenkes, audit kematian tingkat kabupaten tidak dilakukan secara rutin. Kalaupun dilakukan, kegiatan ini tidak memenuhi standar nasional (Hyre, Caiola, Amelia, Gandawidjaja, Markus, \& Baharuddin, 2019). Hanya Malaysia yang mendiseminasikan rekomendasi hasil audit pada tingkat nasional, sementara di Indonesia hanya dilakukan pada tingkat fasilitas saja (Bandali, Thomas, Hukin, Matthews, Mathai, Ramachandran Dilip, et al., 2016). WHO merekomendasikan agar temuan-temuan "disebarluaskan menggunakan berbagai saluran untuk memungkinkan banyak orang mengaksesnya dan memastikan bahwa informasi tersebut sampai kepada mereka yang dapat menindaklanjutinya" (WHO, UNFPA, \& CDC, 2013) .

Kementerian kesehatan mendefinisikan audit maternal sebagai proses untuk menelusuri penyebab kesakitan maupun kematian maternal dalam rangka mencegah kejadian serupa di masa akan datang (Kementerian Kesehatan Republik Indonesia, 2016). Audit maternal bertujuan untuk mengubah organisasi pelayanan kesehatan melalui implementasi rekomendasi berdasarkan temuan audit ( PozoRodríguez, Castro-Acosta, \& Álvarez-Martínez, 2015). Sebagai inti clinical governance, audit klinis semacam audit maternal dibangun di atas budaya profesional kesehatan, yang secara tradisional menggunakan dan mempelajari catatan kasus dan menggali informasi yang reliabel dalam rangka menentukan arah perbaikan dan peningkatan kualitas pelayanan (Chambers \& Wakley, 2005).

Organisasi termasuk pelayanan kesehatan, umumnya mempunyai birokrasi yang rumit dan kaku, sehingga sangat sulit untuk melaksanakan perubahan organisasi. Perubahan dalam organisasi layanan kesehatan dipengaruhi oleh banyak faktor, semacam kenaikan biaya perawatan, kekurangan tenaga kerja, kewajiban profesional, tata kelola klinis dan kode etik, kemajuan Ilmu Pengetahuan, penuaan populasi, kepuasan pasien, maupun promosi keselamatan pasien dan staf (Mitchell, 2012). Pelayanan kesehatan umumnya menuntut otonomi tingkat tinggi dan pemikiran mandiri, sehingga individu di dalamnya umumnya mengalami kesulitan menerima perubahan begitu saja tanpa bukti ilmiah yang jelas dan meyakinkan. Tingkat kematian ibu yang masih tinggi memerlukan tindakan 
kolaboratif semua pihak berdasarkan evidence-based, yang dilakukan secara berkelanjutan, terarah dan terencana.

Tantangan lainnya adalah rasio kegagalan perubahan organisasi terencana yang mencapai 60 70\% ( Palmer, Richard, \& Buchanan, 2017). Survey lainnya oleh McKinsey menemukan bahwa tingkat keberhasilan perubahan transformasional hanya 26 persen, padahal perubahan diperlukan untuk meningkatkan kinerja dan memungkinkan organisasi untuk mempertahankan peningkatan secara berkelanjutan ( Jacquemont, Maor, \& Reich, 2015).

Salah satu unsur dalam perubahan organisasi adalah perilaku organisasi, yaitu bagaimana pengaruh perilaku manusia terhadap kinerja organisasi. Penerapan ilmu perilaku organisasi akan meningkatkan efektivitas organisasi. Perilaku organisasi sangat erat kaitannya dengan pengambilan keputusan, kepemimpinan, motivasi, kepribadianz, produktivitas, kinerja dan manajemen manusia. Perilaku organisasi dipengaruhi oleh individu, kelompok dan struktur organisasi yang terlibat dalam proses berkelanjutan yaitu input, process, dan outcome (Robbins \& Judge, 2017).

Audit klinis yang baik harus memiliki tahapan kegiatan yang terukur agar dianggap berkualitas tinggi. Healthcare Quality Improvement Partnership (HQIP) menetapkan sebuah siklus dalam proses audit dengan kriteria dan indikator pelaksanaan yang harus terpenuhi agar audit klinis menjadi sebuah proses yang berkualitas. Tahapan-tahapan ini, dan indikator kualitas di dalamnya, merupakan aspek umum dalam audit klinis, beberapa aspek berbeda mungkin diperlukan pada tatanan yang berbeda (Healthcare Quality Improvement Partnership, 2018).

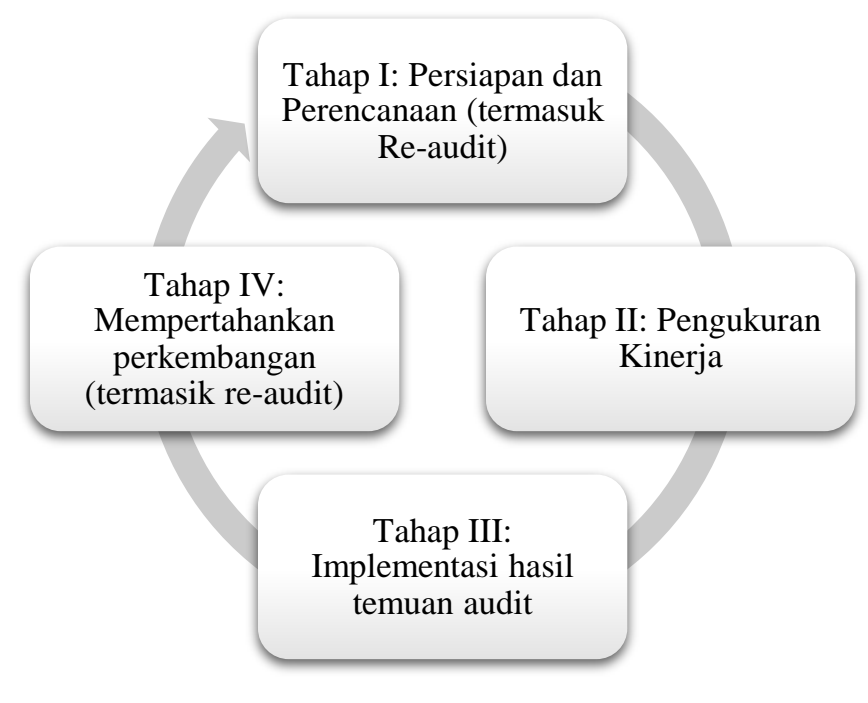

Gambar 1. Siklus audit klinis, berdasarkan rekomendasi Healthcare Quality Improvement Partnership (HQIP)

Sumber: Healthcare Quality Improvement Partnership, (2018)

Secara doktrinal, audit maternal dilakukan dalam rangka penilaian tindakan kedokteran di Rumah Sakit ataupun layanan kesehatan lain. Audit akan menilai sebuah tindakan/pelayanan di institusi pelayanan kesehatan, berdasarkan pada standar pelayanan minimal yang ditetapkan fasilitas kesehatan. Namun, seringkali rekomendasi dari temuan audit tidak diimplementasikan (Taylor, Neuburger, Walker, Cromwell, \& Groene, 2016), sehingga tidak terjadi perubahan yang diharapkan. Perilaku dan 
budaya dalam organisasi, semacam kepemimpinan, kebijakan, maupun dukungan sumber daya, seringkali menjadi resistensi dalam proses perubahan tersebut, atau dapat dikatakan bahwa siklus audit tidak tertutup.

Review sebelumnya telah banyak mengidentifikasi kendala dan hambatan audit maternal dan audit medis. Namun belum ditemukan review terkait subjek penelitian dalam konteks perubahan dan perilaku organisasi. Sehingga pertanyaan penelitian adalah, faktor organisasi apa saja yang menghambat audit maternal, sedangkan tujuan penelitian adalah menemukan faktor-faktor organisasi yang menghambat audit maternal. Hasil penelitian ini diharapkan dapat membantu pemangku kebijakan dan pengambil keputusan perlu memahami aspek-aspek organisasi yang berjalan suboptimal dalam pelaksanaan audit. Hal ini diharapkan dapat membantu semua pihak dalam berkolaborasi dalam rangka menutup siklus audit menjadi sebuah proses yang berkelanjutan, terarah dan terencana.

\section{METODE RISET}

Ini adalah penelitian kualitatif dengan pendekatan narrative review terkait perilaku organisasi yang mempengaruhi pelaksanaan audit maternal. Penelitian ini menggunakan sumber data sekunder yang berasal dari artikel-artikel penelitian terdahulu. Data diperoleh melalui penelusuran dari database PubMed dan Sciencedirect. Penelusuran artikel dilakukan dengan cara menggabungkan kata kunci menggunakan kata “AND”, “OR”, ataupun "NOT”. Kata kunci yang digunakan antara lain "obstacles”, "barriers", "clinical audit" dan "maternal audit". Data penelitian dianalisis dengan metode content analysis.

Penelusuran menemukan sebanyak 93 artikel dari tahun 2001 hingga 2020 dengan kata kunci pencarian di atas. Artikel-artikel duplikasi disingkirkan dan menyisakan sebanyak 38 artikel. Selanjutnya abstrak setiap artikel dibaca dan yang tidak sesuai disingkirkan dari penelitian. Sebanyak 7 artikel yang sesuai dengan tujuan penelitian dianalisis untuk menemukan berbagai hambatan dan kendala dalam pelaksanaan audit maupun implementasi hasil audit. Hambatan-hambatan tersebut dikelompokkan berdasarkan konteks perilaku organisasi yaitu individu, kelompok dan struktur organisasi (Robbins \& Judge, 2017).

\section{HASIL PENELITIAN DAN PEMBAHASAN}

Hasil analisis menemukan bahwa terdapat kompleksitas terkait pelaksanaan audit maupun implementasi hasil audit. Tabel 1 menyajikan berbagai bentuk kendala audit yang telah dikelompokkan berdasarkan komponen dalam perilaku organisasi, yaitu individu, kelompok, dan struktur organisasi. Perilaku persekusi oleh individu maupun kelompok (Bayley et al., 2015; Stokes et al., 2016) dan budaya menyalahkan (Kediegile \& Madzimbamuto, 2014; Lewis, 2014; Stokes et al., 2016) dalam organisasi kemungkinan terjadi akibat tidak adanya jaminan terhadap kerahasiaan dan pengungkapan data selama proses audit (Stokes et al., 2016). Pelaksanaan audit maternal didasarkan atas asas prinsip atau asas 
yang harus dipertahankan selama proses audit, yaitu no name (tidak menyebutkan identitas), no shame (tidak mempermalukan), no blame (tidak menyalahkan), no pro justitia (tidak untuk kepentingan peradilan), dan pembelajaran (Smith et al., 2017). Audit maternal diharapkan dapat menemukan sebab dan faktor-faktor terkait dalam kesakitan/kematian ibu dan perinatal, baik tempat dan alasan, maupun sistem dan program, yang gagal dalam mencegah kematian, serta jenis intervensi yang dibutuhkan.

Tabel 1. Kendala proses audit maternal

\begin{tabular}{ll}
\hline Individu & 1) Kekhawatiran dipersekusi (Bayley et al., 2015; Stokes et al., 2016) \\
2) Tidak adanya jaminan kerahasiaan terkait pengungkapan data (Stokes et al., 2016) \\
3) Kepatuhan rendah terhadap rekomendasi audit (Kediegile \& Madzimbamuto, 2014) \\
4) Keengganan untuk menjalani perubahan, terutama karena adanya anggapan "semua sulit \\
dilakukan" (Esposito, 2014; Lewis, 2014; Prasad \& Reddy, 2004) \\
5) Kurangnya motivasi staff maupun auditor (Stokes et al., 2016; Reza Gholi Vahidi et al., \\
\\
6) 2013 ) \\
7) Motivasi perubahan rendah (Stokes et al., 2016)
\end{tabular}

Kelompok 1) Perilaku kelompok dan kerjasama yang rendah (R G Vahidi et al., 2013)

2) Lingkungan kerja yang kurang mendukung (Vargas et al., 2020)

3) Eksklusivitas; adanya anggapan bahwa hanya perawat dan bidan saja yang diaudit (Stokes et al., 2016)

4) Adanya budaya persekusi dan melempar kesalahan (Kediegile \& Madzimbamuto, 2014; Lewis, 2014; Stokes et al., 2016)

5) Pengambilan keputusan secara praktis tanpa memperhatikan akar penyebab masalah (Lewis, 2014)

6) Pembagian data pada beberapa staff menyulitkan pengambilan data (Stokes et al., 2016)

7) Rendahnya umpan balik terkait rekomendasi, termasuk manajemen (Stokes et al., 2016)

8) Bersikap resisten terhadap perubahan (Stokes et al., 2016)

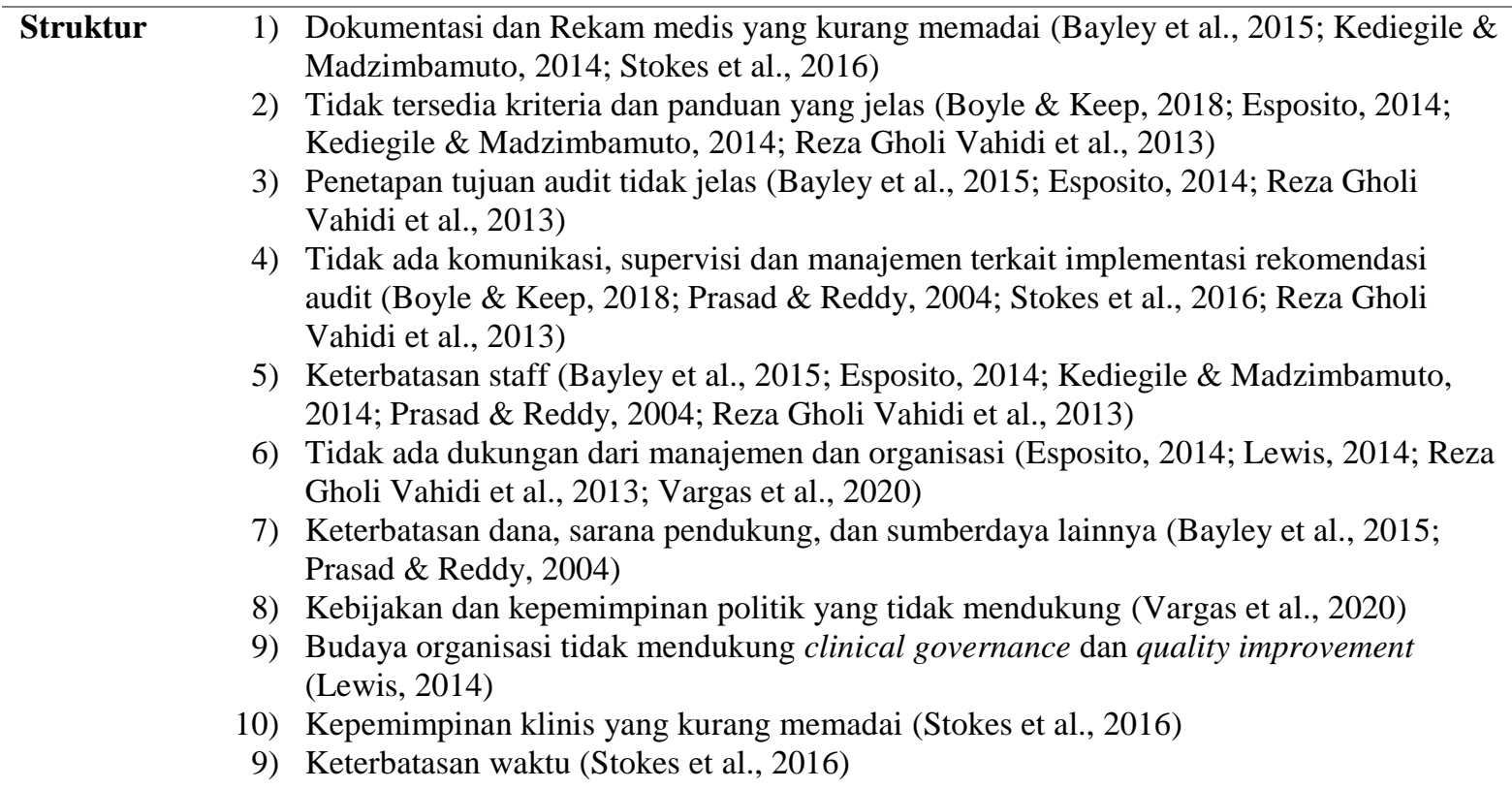

Sumber: Data Primer, 2020

Proses audit maternal memerlukan perlindungan hukum yang jelas terkait akses informasi rumah sakit, perlindungan terhadap orang-orang yang terlibat (health provider, penyelidik, maupun anggota keluarga) dalam proses review kematian maternal, termasuk penggunaan hasil review (Bain \& Kongnyuy, 2018). Ketentuan undang-undang terkait dengan kepemilikan, akses dan penggunaan rekam 
medis, perlindungan staf kesehatan yang terlibat dalam proses audit dan potensi penggunaan temuannya perlu didefinisikan secara jelas. Pedoman khusus negara berdasarkan undang-undang akan membantu mengurangi potensi ketegangan yang mungkin terjadi selama proses audit maupun implementasi hasil audit (Bain \& Kongnyuy, 2018). Proses audit maternal akan mengungkapkan cerita di balik kematian ibu guna memberikan informasi, sehingga akan menghilangkan hambatan pelayanan, tetapi temuan ini harus ditindaklanjuti melalui perubahan nyata pada tingkat kebijakan, program, maupun fasilitas kesehatan itu sendiri (Bandali et al., 2016).

Adanya resistensi perubahan dalam implementasi hasil audit (Semple et al., 2000), dapat disebabkan oleh adanya ketakutan terhadap sesuatu yang belum pasti, sehingga muncul anggapan "semua sulit dilakukan" (Esposito, 2014; Lewis, 2014; Prasad \& Reddy, 2004), atau merupakan manifestasi dari ketakutan akan sesuatu yang tidak diketahui (S. Robbins \& Timothy, 2018). Hal ini menyebabkan motivasi perubahan yang rendah di antara anggota organisasi (Semple et al., 2000; Stokes et al., 2016). Resistensi perubahan dapat berupa penolakan terhadap proses perubahan itu sendiri, namun lebih tepatnya merupakan penolakan terhadap kehilangan sesuatu yang berharga bagi orang tersebut (Burke, 2018). Ditemukannya praktik berdasarkan "personal believes' (Prasad \& Reddy, 2004), pengambilan keputusan secara praktis tanpa memperhatikan akar penyebab masalah (Lewis, 2014), dan rendahnya umpan balik terkait rekomendasi (Stokes et al., 2016) menunjukkan bahwa anggota organisasi berusaha mempertahankan posisi aman yang telah dimilikinya (S. Robbins \& Timothy, 2018).

Komunikasi yang efektif dan intens dengan staf tentang manfaat perubahan sangat penting, begitu pula mendengarkan kekhawatiran mereka. Staf juga harus dilibatkan dalam proses menghasilkan ide perubahan dan strategi penerapan perubahan (Thompson, 2010). Keterlibatan memungkinkan staf untuk mendapatkan umpan balik secara cepat tentang bagaimana perubahan bekerja, bagaimana mengintegrasikan perubahan dalam peran mereka, dan untuk mengidentifikasi sumber potensial dan alasan resistensi (Willis et al., 2016).

Temuan penelitian ini menunjukkan bahwa layanan kesehatan mengalami kesulitan dalam penetapan tujuan audit (Bayley et al., 2015; Esposito, 2014; Reza Gholi Vahidi et al., 2013), ataupun mengalami kendala komunikasi, supervisi dan manajemen terkait implementasi rekomendasi audit (Boyle \& Keep, 2018; Prasad \& Reddy, 2004; Stokes et al., 2016; Reza Gholi Vahidi et al., 2013). Hal ini menunjukkan bahwa tidak adanya mekanisme perencanaan yang terintegrasi sehingga membatasi penyelarasan audit dengan tujuan organisasi (McErlain-Burns \& Thomson, 1999) yang menunjukkan pentingnya kepemimpinan dalam proses audit demi perubahan berkelanjutan berdasarkan bukti temuan audit (Willis et al., 2016). Kepemimpinan dan motivasi yang baik sangat penting untuk memastikan kontinuitas dalam audit maternal dan mencegah penurunan motivasi anggota organisasi (Kongnyuy \& van den Broek, 2008). Keterampilan kepemimpinan yang efektif, terutama oleh dokter, untuk mengelola perubahan akan menginspirasi komitmen dalam tim pelayanan (Fry \& Dombkins, 2017). 
Temuan lain dalam penelitian ini adalah kurangnya data akibat dokumentasi yang buruk (underreporting). Kejadian ini merupakan masalah klasik dalam proses audit maternal. Kasus under-reporting mengindikasikan adanya proses dokumentasi pelayanan yang tidak berjalan sebagaimana mestinya. Suatu audit medis dianggap layak, jika terdapat dua elemen penting, yaitu 1) adanya standar praktik yang baik, dan 2) ketersediaan catatan kualitas yang baik dari manajemen klinis. Jika catatan tidak ada atau tidak disimpan dengan baik, maka akan sulit untuk melakukan audit, berdasarkan prinsip: "jika tidak dicatat, itu tidak terjadi" (Brouwere, Zinnen, \& Delvaux, 2013).

Dokumentasi pelayanan merupakan salah satu tanggung jawab petugas pelayanan kesehatan. UU Kedokteran menyebutkan bahwa setiap dokter dalam menjalankan praktik kedokteran wajib membuat rekam medis yang segera dilengkapi setelah pasien selesai menerima pelayanan kesehatan dan harus dibubuhi nama, waktu, dan tanda tangan petugas yang memberikan pelayanan atau tindakan (Pasal 46 UU 29 Tahun 2004 Tentang Praktik Kedokteran). UU Rumah Sakit juga menyebutkan bahwa dalam penyelenggaraan rumah sakit harus mengadakan rekam medis sesuai standar (Penjelasan Pasal 29 ayat (1) huruf (h) UU Nomor 44 Tahun 2009 Tentang Rumah Sakit). Rumah sakit juga harus melakukan pencatatan dan pelaporan tentang semua kegiatan penyelenggaraan Rumah Sakit yang dilaksanakan sesuai dengan ketentuan peraturan perundang-undangan (UU Nomor 44 Tahun 2009 Tentang Rumah Sakit Lihat Pasal 52). Walaupun rumah sakit berkewajiban untuk menjaga rahasia kedokteran (UU Nomor 44 Tahun 2009 Tentang Rumah Sakit Lihat Pasal 44), tetapi dalam proses audit medis setiap informasi tidak boleh ditutupi, karena memang sifatnya terbatas dan demi kemaslahatan warga negara yang lebih luas.

Kendala lain yang ditemukan adalah kurangnya dukungan dari organisasi maupun manajemen. Dukungan manajemen dalam implementasi hasil audit memiliki daya ungkit yang sangat besar dalam proses perubahan organisasi. Manajemen dapat terus berupaya untuk meningkatkan efikasi diri karyawan, sikap terkait perubahan, dan persepsi kendali atas situasi untuk menciptakan orientasi perubahan yang positif (S. Robbins \& Timothy, 2018). Strategi yang dapat digunakan misalnya klarifikasi peran dan penghargaan berkelanjutan untuk meningkatkan efikasi diri, dan meningkatkan kontrol dan sikap positif terhadap perubahan dengan memasukkan staf dalam seluruh tahap perencanaan. Manajemen juga harus meningkatkan intensitas komunikasi dengan staf selama perubahan, menilai dan meningkatkan ketahanan psikologis staf melalui dukungan sosial, dan pelatihan teknik pengaturan diri emosional. Melalui metode ini, manajer dapat membantu karyawan menjaga tingkat stres mereka rendah dan komitmen mereka tetap tinggi (S. Robbins \& Timothy, 2018). Bentuk dukungan lain adalah meningkatkan kemampuan organisasi dalam penyediaan sumberdaya dan sarana prasarana yang dibutuhkan untuk mencapai kondisi perubahan yang diharapkan.

Dukungan pemerintah melalui kebijakan juga menjadi problem dalam pelaksanaan audit maternal. Percepatan dalam mengurangi angka kematian ibu memerlukan intervensi klinis dan nonklinis, sekaligus kebijakan politis. Proses perubahan yang dilandasi kebijakan yang komprehensif akan $\underline{\text { memberikan rasa aman dalam pelaksanaan audit, terutama berkaitan dengan pengungkapan data rahasia }}$ 
rumah sakit. Pemerintah daerah merupakan pembina dalam struktur audit maternal (Undang-Undang Nomor 25 Tahun 2009 Tentang Pelayanan Publik, 2009), yang bertugas mengoordinasikan kelancaran penyelenggaraan audit sesuai pedoman audit maternal yang ditetapkan pemerintah dan melakukan evaluasi penyelenggaraan audit.

\section{KESIMPULAN DAN SARAN}

Penyelenggaraan audit maternal membutuhkan komitmen semua anggota organisasi demi tercapainya tujuan audit, yaitu peningkatan kualitas pelayanan kesehatan. Berbagai hambatan pelaksanaan audit maternal menyebabkan audit tidak cukup memberikan dampak signifikan dalam usaha penurunan angka kematian ibu. Isu terkait budaya persekusi dan menyalahkan, kurang lengkapnya catatan dan dokumentasi, dukungan sumberdaya maupun manajemen yang rendah, maupun kepemimpinan klinis dan politis merupakan masalah klasik dalam pelaksanaan audit maternal.

Oleh karena itu, audit maternal membutuhkan legalitas agar dapat berkekuatan hukum. Percepatan dalam mengurangi angka kematian ibu memerlukan intervensi klinis dan non-klinis, sekaligus kebijakan politis. Sehingga audit maternal menjadi bagian dari pengawasan rutin dan pemantauan hasil kesehatan ibu. Penyusunan kebijakan, proses analisis, maupun aksi tindak lanjut terkait audit maternal juga harus melibatkan setiap unsur organisasi, baik individu maupun kelompok dalam struktur organisasi. Komitmen pemerintah, manajemen dan administrasi diharapkan dalam mobilisasi sumber daya dan dukungan dalam proses audit. Organisasi juga harus mengembangkan budaya yang suportif di semua tingkatan dalam pembelajaran. Selain itu diperlukan kerjasama multidisiplin yang meninjau dan mengkomunikasikan temuan di berbagai tingkat sistem kesehatan. Hal ini akan memastikan ketersediaan informasi untuk mendorong praktik berdasarkan bukti.

Penelitian ini hanya berfokus pada kendala audit dilihat dari sisi perilaku organisasi secara kualitatif. Aspek hambatan audit kemungkinan akan berbeda pada setiap tatanan yang berbeda. Analisis empiris secara kuantitatif terkait hambatan-hambatan tersebut akan dapat membuktikan aspek yang paling berpengaruh terhadap proses audit maternal dalam berbagai tingkatan pelayanan maupun sosial 


\section{DAFTAR PUSTAKA}

Bain, L. E., \& Kongnyuy, E. J. (2018). Legal and ethical considerations during maternal death surveillance and response. African Journal of Reproductive Health, 22(2), 17-25. https://doi.org/10.29063/ajrh2018/v22i2.2

Bandali, S., Thomas, C., Hukin, E., Matthews, Z., Mathai, M., Ramachandran Dilip, T., Roos, N., Lawley, R., Igado, O., \& Hulton, L. (2016). Maternal Death Surveillance and Response Systems in driving accountability and influencing change. International Journal of Gynecology and Obstetrics, 135(3), 365-371. https://doi.org/10.1016/j.ijgo.2016.10.002

Bayley, O., Chapota, H., Kainja, E., Phiri, T., Gondwe, C., King, C., Nambiar, B., Mwansambo, C., Kazembe, P., Costello, A., Rosato, M., \& Colbourn, T. (2015). Community-linked maternal death review (CLMDR) to measure and prevent maternal mortality: A pilot study in rural Malawi. BMJ Open, 5(4). https://doi.org/10.1136/bmjopen-2015-007753

Boyle, A., \& Keep, J. (2018). Clinical audit does not work, is quality improvement any better?. British Journal of Hospital Medicine, 79(9), 508-510. https://doi.org/10.12968/hmed.2018.79.9.508

BPS. (2015). Penduduk Indonesia: Hasil Survei penduduk Antar Sensus 2015. Badan Pusat Statistik.

Brouwere, V. De, Zinnen, V., \& Delvaux, T. (2013). How to conduct Maternal Death Reviews (MDR). Guidelines and tools for health professionals. International Federation of Gynecologists ad Obstetricians. http://www.figo.org/files /figo-corp/EditedMDRGuidelinesfinal2014.pdf

Burke, W. W. (2018). Organization Change (5th ed.). SAGE Publications, Inc.

Chambers, R., \& Wakley, G. (2005). Clinical Audit in Primary Care: Demonstrating Quality and Outcomes. In Abingdon: Radcliffe Publishing. Taylor \& Francis Group.

Esposito, P. (2014). Clinical audit, a valuable tool to improve quality of care: General methodology and applications in nephrology. World Journal of Nephrology, 3(4), 249. https://doi.org/10.5527/wjn.v3.i4.249

Fry, M., \& Dombkins, A. (2017). Interventions to support and develop clinician-researcher leadership in one health district. International Journal of Health Care Quality Assurance, 30(6), 528-538. https://doi.org/10.1108/IJHCQA-07-2016-0104

Healthcare Quality Improvement Partnership. (2018). Criteria and indicators of best practice in clinical audit. Healthcare Quality Improvement Partnership (HQIP). https://www.hqip.org.uk/wpcontent/uploads/2018/02/best-practice-in-clinical-audit.pdf

Hyre, A., Caiola, N., Amelia, D., Gandawidjaja, T., Markus, S., \& Baharuddin, M. (2019). Expanding Maternal and Neonatal Survival in Indonesia: A program overview. International Journal of Gynecology \& Obstetrics, 144, 7-12. https://doi.org/10.1002/ijgo.12730 
Jacquemont, D., Maor, D., \& Reich, A. (2015). How to beat the transformation odds. McKinsey \& Company. https://www.mckinsey.com/business-functions/organization/our-insights/how-to-beatthe-transformation-odds

Kediegile, G., \& Madzimbamuto, F. D. (2014). Obstacles faced when conducting a clinical audit in Botswana. Southern African Journal of Anaesthesia and Analgesia, 20(2), 127-131.

Kementerian Kesehatan Republik Indonesia. (2016). Pedoman Surveilans Kematian Ibu. Kementerian Kesehatan Republik Indonesia.

Kongnyuy, E. J., \& van den Broek, N. (2008). The difficulties of conducting maternal death reviews in Malawi. BMC Pregnancy and Childbirth, 8, 1-7. https://doi.org/10.1186/1471-2393-8-42

Lewis, G. (2014). The cultural environment behind successful maternal death and morbidity reviews. 24-31. https://doi.org/10.1111/1471-0528.12801

McErlain-Burns, T. L., \& Thomson, R. (1999). The lack of integration of clinical audit and the maintenance of medical dominance within British hospital trusts. Journal of Evaluation in Clinical Practice, 5(3), 323-333. https://doi.org/10.1046/j.1365-2753.1999.00195.x

Mitchell, G. (2012). Selecting the best theory to implement planned change. Nursing Management, 20(1), 32-37. www.nursingmanagement.co.uk

Palmer, I., Richard, D., \& Buchanan, D. A. (2017). Managing organizational change: A Multiple Perspecties Approach (3rd ed.). McGraw-Hill Education.

Pozo-Rodríguez, F., Castro-Acosta, A. A., \& Álvarez-Martínez, C. J. (2015). Clinical audit: Why, where and how? Archivos de Bronconeumologia, 51(10), 479-480. https://doi.org/10.1016/j.arbr.2015.08.006

Prasad, K. R. S., \& Reddy, K. T. V. (2004). Auditing the audit cycle: An open-ended evaluation. Clinical Governance, 9(2), 110-114. https://doi.org/10.1108/14777270410536394

Robbins, S. P., \& Judge, T. A. (2017). Organizational Behavior. In Pearson Education Limited (17th ed.). Pearson Education Limited.

Robbins, S., \& Timothy, J. (2018). Essential of Organizational Behaviour. Pearson Education Limited.

Semple, D. M., Khaled, K., \& Maresh, M. J. A. (2000). Monitoring quality of audit in obstetrics and gynaecology. Quality in Health Care, 9(1), 37-41. https://doi.org/10.1136/qhc.9.1.37

Smith, H., Ameh, C., Roos, N., Mathai, M., \& van den Broek, N. (2017). Implementing maternal death surveillance and response: A review of lessons from country case studies. BMC Pregnancy and Childbirth, 17(1), 1-11. https://doi.org/10.1186/s12884-017-1405-6

Stokes, T., Shaw, E. J., Camosso-Stefinovic, J., Imamura, M., Kanguru, L., \& Hussein, J. (2016). Barriers and enablers to guideline implementation strategies to improve obstetric care practice in 
low- and middle-income countries: A systematic review of qualitative evidence. Implementation Science, 11(1), 1-10. https://doi.org/10.1186/s13012-016-0508-1

Taylor, A., Neuburger, J., Walker, K., Cromwell, D., \& Groene, O. (2016). How is feedback from national clinical audits used? Views from English National Health Service trust audit leads. Journal of Health Services Research and Policy, 21(2), 91-100. https://doi.org/10.1177/1355819615612826

Thompson, J. M. (2010). Understanding and managing organizational change: Implications for public health management. Journal of Public Health Management and Practice, 16(2), 167-173. https://doi.org/10.1097/PHH.0b013e3181c8cb51

Undang-Undang Nomor 25 Tahun 2009 Tentang Pelayanan Publik, (2009).

Vahidi, R G, Tabrizi, J. S., Iezadi, S., Gholipour, K., Mojahed, F., \& Rasi, V. (2013). Organizational facilitators and barriers to implementing effective clinical audit: Systematic review. Journal of Pakistan Medical Students, 3(August), 38-45. http://www.jpmsonline.com/wpcontent/uploads/2013/01/JPMS-VOL3-ISSUE1-PAGES38-45-RA.pdf

http://ovidsp.ovid.com/ovidweb.cgi?T=JS\&CSC=Y\&NEWS=N\&PAGE=fulltext\&D=emed11\& $\underline{\mathrm{AN}=2013184086}$

Vahidi, Reza Gholi, Tabrizi, J. S., Iezadi, S., Gholipour, K., Mojahed, F., \& Rasi, V. (2013). Organizational Facilitators and Barriers to Implementing Effective Clinical Audit: Systematic Review. J Pak Med Stud, 3(1), 38-45. http://www.jpmsonline.com/wpcontent/uploads/2013/01/JPMS-VOL3-ISSUE1-PAGES38-45-RA.pdf

Vargas, I., Eguiguren, P., Mogollón-Pérez, A. S., Bertolotto, F., Samico, I., López, J., De Paepe, P., \& Vázquez, M. L. (2020). Understanding the factors influencing the implementation of participatory interventions to improve care coordination. An analytical framework based on an evaluation in Latin America. Health Policy and Planning, 35(8), 962-972. https://doi.org/10.1093/heapol/czaa066

WHO. (2016). Time to respond: A report on the global implementation of Maternal Death Surveillance and Response.

WHO, UNFPA, \& CDC. (2013). Maternal Death Surveillance and Response Techincal Guidance.

WHO, UNICEF, UNFPA, World Bank, \& United Nations Population Division. (2015). Trends in Maternal Mortality: 1990 to 2015. World Health Organization.

Willis, C. D., Saul, J., Bevan, H., Scheirer, M. A., Best, A., Greenhalgh, T., Mannion, R., Cornelissen, E., Howland, D., Jenkins, E., \& Bitz, J. (2016). Sustaining organizational culture change in health systems. Journal of Health, Organisation and Management, 30(1), 2-30. https://doi.org/10.1108/JHOM-07-2014-0117 